\title{
A Laboratory Study of Advertising and Price Competition*
}

\author{
by \\ John Morgan ${ }^{1}$, Henrik Orzen ${ }^{2}$ and Martin Sefton ${ }^{3}$
}

July, 2003

\begin{abstract}
We use a laboratory experiment to study advertising and pricing behavior in a market where consumers differ in price sensitivity. Equilibrium in this market entails variation in the number of firms advertising and price dispersion in advertised prices. We vary the cost to advertise as well as varying the number of competing firms. Theory predicts that advertising costs act as a facilitating device: higher costs increase firm profits at the expense of consumers. We find that higher advertising costs decrease demand for advertising and raise advertised prices, as predicted. Further, this comes at the expense of consumers. However, pricing and advertising strategies are more aggressive than theory predicts with the result that firm profits do not increase.
\end{abstract}

Keywords: Experiments, Price Dispersion, Advertising

JEL Classification Numbers: C72, C92

\footnotetext{
${ }^{*}$ We are grateful to the ESRC for funding the experiments under grant R000 223344 as well as the National Science Foundation. Orzen's work was supported by the Gottlieb Daimler- und Karl Benz- Foundation. We thank participants at seminars in Amsterdam and Edinburgh and the 2002 ESA European Meetings (Strasbourg) for helpful comments and advice.

1. Haas School of Business and the Department of Economics, University of California, Berkeley. e-mail: morgan@haas.berkeley.edu 2. School of Economics, University of Nottingham, Nottingham, NG7 2RD, United Kingdom. e-mail: lexho@nottingham.ac.uk 3. School of Economics, University of Nottingham, Nottingham, NG7 2RD, United Kingdom. e-mail: martin.sefton@nottingham.ac.uk
} 


\section{Introduction}

In contrast to the classical theory of perfectly competitive markets, many markets are characterized by imperfect price information. Consumers often do not know (or perhaps do not care solely about) the prices charged by all sellers in a market, and buyers and sellers must often incur costs to discover or transmit this information. A now well-established literature analyzes how various search frictions can generate imperfect information, and hence affect market performance, and this literature shows that many of the properties of perfectly competitive markets do not carry over to markets with these characteristics. For example, in a market where some consumers are better informed than others about what prices are available, the "Law of One Price" may not hold. That is, in equilibrium, different sellers may charge different prices for a homogeneous product. Moreover, changes in the underlying structure of such markets often have implications that differ quite strikingly from the perfectly competitive case.

For example, Varian’s “Model of Sales” (Varian, 1980) analyzes price competition among identical sellers supplying a homogeneous product. Demand for the product comes from two types of consumer. Informed consumers know the prices charged by different sellers and buy at the lowest price (as long as this does not exceed their reservation price). Uninformed consumers do not know what prices are available, and simply choose a seller at random and buy from this seller (again, supposing that the seller's price does not exceed their reservation price). In this model the unique symmetric equilibrium involves price dispersion as sellers use mixed strategies to generate prices. More broadly, one can view Varian's model as one in which consumers differ in their price sensitivity. Under this view, when consumers are heterogeneous in their price sensitivities, price dispersion is predicted to be the inevitable outcome. 
In a previous paper (Morgan, Orzen and Sefton, 2003) we derived some comparative static implications of this model, and reported an experiment designed to test them. The data showed substantial and persistent price dispersion, and although empirical price distributions deviated somewhat from the theoretical distributions, the model was successful in predicting how average prices varied with changes in the underlying market structure. In particular, we noted that, rather intuitively, prices are predicted to decrease as the proportion of informed consumers increases. This prediction was strongly supported by our experimental data. We also noted that, less intuitively, prices are predicted to increase with the number of competing sellers. Again, this prediction found strong support in our experimental data.

One feature of Varian's model is that the composition of the market faced by a sellerthe numbers of informed and uninformed consumers - is exogenous. Perhaps more importantly, the decision to advertise prices is likewise exogenous. In practice, the decision of how often and at what price to advertise is at the heart of many business decisions. Despite this, the interaction between advertising and pricing strategies of firms has been little studied in laboratory settings.

In a recent paper, Baye and Morgan (2001) study a market where informed consumers receive their information through an "information gatekeeper," which might be thought of as a newspaper or an internet price comparison site. In order to advertise their price, a seller must pay an advertising fee set by the gatekeeper. The model captures the idea that even when some consumers are looking for bargains, sellers must incur costs in order to attract their attention. When there is no advertising fee, the model is identical to Varian's: all sellers advertise and face a mix of informed consumers and uninformed consumers. How does introducing a cost of advertising affect the market? 
In theory the answer is clear-cut. Higher advertising fees reduce sellers' propensity to advertise and result in less intense price competition. As a result, consumers of all price sensitivities end up paying higher prices. Thus, higher advertising fees hurt consumers. In contrast, sellers benefit from higher advertising fees - the reason being that the higher prices charged in equilibrium outweigh the direct, negative, impact on profits of higher advertising costs. Thus, advertising fees can be viewed as a facilitating device, reducing the incentive of sellers to undercut one another, and enabling sellers to attain higher profits.

This theoretical prediction relies on a comparative static analysis of a unique symmetric equilibrium, which involves two levels of mixed strategy. In equilibrium, sellers randomize between advertising and not advertising. Further, sellers that advertise use mixed strategies to choose prices. Thus, while there is a unique symmetric equilibrium, the complexity of computing equilibrium strategies makes it far from obvious that human decision-makers will use equilibrium strategies, or even be able to approximate them.

In a large experimental literature studying matrix games with mixed strategy equilibria systematic departures from equilibrium predictions are commonly observed. However, as Camerer (2003) notes in a recent review, the empirical frequencies with which actions are used are not far from the mixed strategy predictions. Moreover, as game payoffs are varied, behavior changes, and equilibrium does a reasonably good job of predicting the direction in which behavior changes (for example, see Binmore et al., 2001, particularly Figure 5).

Fewer experiments have examined mixed strategies in more applied settings, but the general pattern from these is similar to that observed in matrix games. Deviations from equilibrium are usually statistically significant, but nevertheless the data are 'close' to equilibrium predictions: Camerer, summarizing these results, argues that "Experiments modeled 
after patent races [Rapoport and Amaldoss, 2000; Amaldoss and Jain, 2002] and three-firm spatial location [Collins and Sherstyuk, 2000] show strong and surprising consistency with counterintuitive mixed strategy predictions." ${ }^{2}$ (Camerer, 2003, p.144). Similarly, in posted price markets where equilibria only exist in mixed strategies behavior deviates from theoretical predictions in terms of levels, but conforms with comparative static predictions (Brown-Kruse et al., 1994, Morgan et al., 2003).

This paper reports an experimental test of whether increases in advertising fees leads sellers to post higher prices and achieve higher profits in a simple version of the Baye and Morgan model. The results from our study are consistent with the pattern from previous experiments on mixed strategy equilibria in that: (i) we observe systematic differences between observed and predicted behavior for any given treatment, (ii) the theory correctly predicts the direction of changes in behavior across treatments — as advertising fees increase subjects advertise less frequently and post higher prices.

However, support for comparative static predictions at the level of separate advertising and pricing decisions does not imply support for comparative static predictions at the level of market outcomes - i.e. expected profits and expected prices paid by different types of consumer. Indeed, an important consideration in the equilibrium is the interaction of the advertising and pricing decisions of firms. Thus, we examine the impact of these interactions on consumers and firms. Theory predicts that consumers will be hurt by higher advertising costs and indeed we find strong support for this in the data. Theory also predicts that firm profits increase from higher advertising costs; however, we do not find much evidence to support this. Our results instead

\footnotetext{
${ }^{2}$ Parentheses added.
} 
suggest that the only party unambiguously helped by higher advertising costs is the recipient of these fees - the information gatekeeper.

The remainder of the paper is organized as follows. In Section 2 we briefly describe the theoretical model, in Section 3 the experimental design and procedures, and in Section 4 the results. Section 5 concludes.

\section{Theory}

\subsection{A Model of Advertising and Price Competition}

In this section, we study a simple variant of Baye and Morgan's (2001) model of information gatekeepers. Consider a homogeneous product market in which there are $n$ competing sellers. Each seller is identical and has a constant marginal cost of production, which we normalize to be zero, and no capacity constraints. Each seller simultaneously chooses a price, $p$, and decides whether or not to advertise. A seller that decides to advertise pays an advertising fee, $\phi$, to do so.

Demand in this market comes from $N$ consumers, each of demands one unit up to a price of $r$. We suppose that a number $\mu$ of consumers are price sensitive "bargain-hunters" and make purchasing decisions by comparing advertised prices. These consumers each purchase one unit from the seller advertising the lowest price, provided that this price does not exceed $r$. In the event that no sellers advertise, or in the event that all advertised prices exceed $r$, these consumers then choose a seller at random and buy from this seller as long as its price does not exceed $r$. Otherwise, these consumers do not purchase. The remaining $N-\mu$ consumers are price insensitive "brand-loyal" consumers. These consumers are assumed to be evenly divided among 
the $n$ sellers, and simply purchase from the seller to whom they are loyal so long as that seller's price does not exceed $r$. Otherwise, they do not purchase the item. ${ }^{3}$

\subsection{Equilibrium}

The nontrivial cases of the theory model occur when the advertising fee is not set prohibitively high, specifically that $\phi<r \mu(n-1) / n$. We may then use techniques analogous to those in Baye and Morgan to obtain a unique symmetric equilibrium. In this equilibrium, sellers advertise with probability

$$
\alpha=1-\left(\frac{n \phi}{(n-1) \mu r}\right)^{\frac{1}{n-1}} .
$$

When a seller chooses not to advertise, it can do no better than to choose a price equal to the consumer's willingness to pay, $r$. When a seller does advertise, it prices according to the cumulative distribution function

$$
F(p)=\frac{1}{\alpha}\left(1-G(p)^{\frac{1}{n-1}}\right)
$$

with support $\left[p_{0}, r\right]$, where

$$
G(p)=\frac{(r-p)(N-\mu) / n+n \phi /(n-1)}{\mu p}
$$

and

$$
p_{0}=\frac{r(N-\mu) / n+n \phi /(n-1)}{\mu+(N-\mu) / n} .
$$

\footnotetext{
${ }^{3}$ While the assumptions about consumers represent the polar case of extreme price sensitivity (for "bargain hunters") and insensitivity (for "loyals"), the conclusions of the model remain qualitatively unchanged if we relax these assumptions. For instance, the model is intact if we allow for some fraction of price sensitive consumers to buy at higher than the lowest price, perhaps due to decision errors. Likewise, the results of the model are not qualitatively affected by allowing consumers the use of more complicated search strategies. Finally, one can view "loyal" consumers as simply less informed consumers who purchase from a firm chosen randomly. See Baye and Morgan (2001).
} 
Using these equilibrium conditions, one can show that a seller's expected profits are

$$
E[\pi]=r \frac{N-\mu}{n}+\frac{\phi}{n-1} .
$$

Expressed this way, sellers' expected profits have a number of intuitive comparative static implications. Profits are increasing in consumers' willingness to pay, $r$. Profits are also increasing in the size of the price insensitive consumer segment $(N-\mu)$. In contrast, profits are declining in the degree of rivalry $(n)$ in the market. Perhaps most striking is that profits are increasing in the level of advertising fees $(\varphi)$. We return to this implication in greater detail later in this section.

Turning to consumers, since all prices are at or below the willingness to pay, consumers' surplus depends solely on the prices prevailing in the market. The average prices paid by each type of consumer are calculated as follows: A loyal consumer obtains the price charged by the seller to which she is loyal. With probability $1-\alpha$ this seller will not advertise and will charge $r$, and with probability $\alpha$ this seller will advertise and charge a price from the pricing distribution $F$. Hence, a loyal consumer expects to pay

$$
E[p]=(1-\alpha) r+\alpha \int_{p_{0}}^{r} p d F(p)
$$

Integrating by parts, we can rewrite this as

$$
\begin{aligned}
E[p] & =(1-\alpha) r+\alpha\left(r-\int_{p_{0}}^{r} F(p) d p\right) \\
& =r-\int_{p_{0}}^{r} \alpha F(p) d p \\
& =p_{0}+\int_{p_{0}}^{r}(1-\alpha F(p)) d p \\
& =p_{0}+\int_{p_{0}}^{r} G(p)^{\frac{1}{n-1}} d p .
\end{aligned}
$$


Price conscious shoppers can expect to pay less than this. With probability $(1-\alpha)^{n}$ no seller will advertise, all sellers will charge $r$, and price conscious consumers will pay $r$. Otherwise $k$ of the $n$ sellers will advertise, and a price conscious consumer will pay the lowest of the $k$ prices. Hence, a price conscious consumer expects to pay

$$
\begin{aligned}
E\left[p_{\min }\right] & =(1-\alpha)^{n} r+\sum_{k=1}^{n} \frac{n !}{k !(n-k) !}(1-\alpha)^{n-k} \alpha^{k} \int_{0}^{r}(1-F(p))^{k} d p \\
& =\int_{0}^{r} \sum_{k=0}^{n} \frac{n !}{k !(n-k) !}(1-\alpha)^{n-k}(\alpha-\alpha F(p))^{k} d p
\end{aligned}
$$

If we apply the binomial theorem this expression simplifies to:

$$
\begin{aligned}
E\left[p_{\text {min }}\right] & =\int_{0}^{r}(1-\alpha+\alpha-\alpha F(p))^{n} d p \\
& =p_{0}+\int_{p_{0}}^{r}(1-\alpha F(p))^{n} d p \\
& =p_{0}+\int_{p_{0}}^{r} G(p)^{\frac{n}{n-1}} d p .
\end{aligned}
$$

Thus, changes in the prevailing price levels depend on changes in $p_{0}$ and $G$. For some parameters these comparative static effects are intuitive. For instance, as a consumer's willingness to pay increases, both $p_{0}$ and $G$ increase and consumers end up paying higher prices. Likewise, as the size of the loyal market $(N-\mu)$ increases, prices again increase for all consumers. The more interesting comparative static effects concern changing advertising fees or increasing rivalry among firms.

\subsection{Comparative Statics}

Before proceeding it is useful to note that:

$$
\frac{\partial p_{0}}{\partial \phi}=\frac{n /(n-1)}{\mu+(N-\mu) / n}>0 \text { and } \frac{\partial G(p)}{\partial \phi}=\frac{n /(n-1)}{\mu p}>0 .
$$




\subsubsection{Changes in Advertising Fees}

What impact do increases in advertising fees have on equilibrium outcomes? We first show that for sellers, increases in advertising fees serve as a facilitating device and raise profitability. This may be seen directly since

$$
\frac{d E \pi}{d \phi}=\frac{1}{n-1}>0
$$

Why do sellers' profits increase with increases in advertising fees? Although the higher advertising fee represents a direct increase in costs, two effects more than offset this. First, as advertising fees increase this reduces the demand for advertising. Second, with less advertising price competition is less fierce and so average prices increase. To see that an increase in fee lessens the demand for advertising, note that

$$
\frac{d \alpha}{d \phi}=\frac{-1}{\phi(n-1)}\left(\frac{n \phi}{(n-1) \mu r}\right)^{\frac{1}{n-1}}<0 .
$$

While this may or may not (depending on the sign of $\left(\frac{n-1}{n}\right)^{n} \mu r-\phi$ ) save a seller directly on total advertising costs, the reduction in advertising does have the effect of blunting direct price competition between sellers advertising prices. As a consequence, the average price each seller charges is higher with higher advertising fees. To see this, notice that

$$
\frac{d E[p]}{d \phi}=\int_{p_{0}}^{r} \frac{1}{(n-1)} G(p)^{\frac{1}{n-1}-1} \frac{\partial G(p)}{\partial \phi} d p>0,
$$

where the inequality comes from the fact that $G(p)$ and $\frac{\partial G(p)}{\partial \phi}$ are positive for all $p$. This price increase is felt directly by brand loyal consumers, who pay the expected price charged by each firm. The reason loyal consumers are paying higher prices is twofold. First, firms are advertising 
less and charging the reservation price $r$ more often. Second, when they do advertise, the distribution of advertised prices shifts. No general stochastic ordering is possible for the change in the distribution of advertised prices with changes in $\phi$; nonetheless, the above result shows that the first effect dominates regardless of the changes in the distribution of advertised prices.

In addition, the lessening price competition results in a higher price to price-sensitive "bargain-hunting" consumers. To see this, notice that

$$
\frac{d E\left[p_{\min }\right]}{d \phi}=\int_{p_{0}}^{r} \frac{n}{(n-1)} G(p)^{\frac{n}{n-1}-1} \frac{\partial G(p)}{\partial \phi} d p>0,
$$

where again the inequality follows from the fact that $G(p)$ and $\frac{\partial G(p)}{\partial \phi}$ are positive for all $p$. For price conscious consumers, the increase in expected prices arises from the fact that the distribution of the number of price listings decreases. Even if there were no strategic effect on the distribution of advertised prices, this would result in higher average prices to these consumers. At the same time, there is a change in the distribution of advertised prices. While this change can go in either direction, the first effect always dominates and price conscious consumers end up paying higher prices.

In our experiment, we manipulate the level of advertising fees across treatments to test these comparative static implications. Specifically, with higher advertising fees, advertising demand is predicted to be lower, profits higher, and prices paid by both types of consumers are predicted to be higher. Our experiment tests these predictions separately for the cases where two and four sellers are competing in the market. 


\subsubsection{Changes in the Number of Competitors}

This design also allows us to examine the effect of changes in the number of competitors. This would seem particularly relevant given the recent upheavals in e-retailing and the demise of many sellers there. An increase in the number of sellers reduces expected profits:

$$
\frac{d E \pi}{d n}=-\frac{r(N-\mu)}{n^{2}}-\frac{\phi}{(n-1)^{2}}<0 .
$$

However, in other cases comparative static predictions with respect to $n$ are parameter specific. For example, advertising propensities are predicted to change with $n$ according to

$$
\frac{d \alpha}{d n}=\left(\frac{n \phi}{(n-1) \mu r}\right)^{\frac{1}{n-1}} \frac{1}{(n-1)^{2}}\left(\frac{1}{n}+\ln \left(\frac{n \phi}{(n-1) \mu r}\right)\right) .
$$

The last term in parentheses is decreasing in $n$, so if this term is negative when $n=2$ it is negative for all $n$. Therefore, if $\phi<\frac{\mu r}{2} e^{-\frac{1}{2}}$, then advertising propensities decrease with $n$.

However, if $\phi>\frac{\mu r}{2} e^{-\frac{1}{2}}$ advertising propensities at first increase, and then decrease, with $n$.

Similarly, it can be shown that, depending on the specific parameter values, expected prices can either increase or decrease with $n$. For example, when $\phi=0$ the model reduces to the simpler model examined in Morgan et al. where all sellers advertise, and so expected prices (and therefore the expected price paid by loyal consumers) increase with $n$. On the other hand, it can be shown that for other values of $\phi$ an increase in the number of competitors decreases expected prices (we give an example later).

Nevertheless, the model allows us to predict the effect of a change in market parameters on equilibrium outcomes. In the case of changes in advertising fees the qualitative predictions are robust in the sense that they hold across the entire range of parameter values. In the case of 
changes in the number of competitors, the qualitative predictions usually depend upon the precise values of market parameters.

\section{Experimental Design and Procedures}

The experiment consisted of 12 sessions conducted at the University of Nottingham during Fall 2001 and Spring 2002. Subjects were recruited from a distribution list comprised of undergraduate students from across the entire university who had indicated a willingness to be paid volunteers in decision-making experiments. For this experiment subjects were sent an email invitation promising to participate in a session lasting approximately 90 minutes, for which they would receive a $£ 3$ show-up fee plus an additional amount that would depend on decisions made during a session. ${ }^{4}$

Twelve subjects participated in each session, and no subject appeared in more than one session. Throughout the session, no communication between subjects was permitted, and all choices and information were transmitted via computer terminals. At the beginning of a session, the subjects were seated at computer terminals and given a set of instructions, which were then read aloud by the experimenter. ${ }^{5}$

The session then consisted of three phases of twenty periods each. At the beginning of each period, subjects were randomly assigned to groups of either two (Two-seller sessions) or four (Four-seller sessions) sellers, and then simultaneously chose prices from the set $\{0,1,2, \ldots$, $100\}$ and decided whether or not to advertise their price in each period.

Each group faced twenty-four computerized buyers who bought one unit each. Twelve of these buyers corresponded to price sensitive bargain-hunters. These buyers were programmed to

\footnotetext{
${ }^{4}$ At the time of the experiment the exchange rate was approximately $£ 1=\$ 1.50$.

${ }^{5}$ A copy of the instructions is included as Appendix A.
} 
buy a unit from whichever seller advertised the lowest price. (In the case of ties for the lowest price, purchases were divided equally among the tied sellers; in the event that no seller advertised its price, purchases were evenly divided among all sellers in a group.) The remaining twelve buyers corresponded to price insensitive loyal consumers. These buyers were evenly divided among all sellers in a group.

After all subjects had submitted their prices, profits for each seller, denominated in 'points', were calculated as (price $\times$ quantity) less any advertising fees incurred. At the end of each period a 'Results Screen' was displayed on each terminal. This screen listed all twelve prices and advertising decisions submitted in the period, together with the associated quantities, highlighting the prices and quantities for that subject's competitor(s). The screen also informed subjects of their own point earnings for that period, the previous five periods, as well as accumulated point earnings.

At the end of the session, subjects were paid the show-up fee plus $1 \mathrm{p}$ per 30 points accumulated over all sixty periods. Earnings averaged $£ 18.97$ (Two-seller sessions) and $£ 8.93$ (Four-seller sessions) for sessions lasting between 50 and 80 minutes.

In six of the sessions, which we refer to as our 'Hi-Lo-Hi' sessions, sellers faced a high cost of advertising $(\phi=400)$ in the first phase of twenty periods, a low cost of advertising ( $\phi=$ $200)$ in the second phase (periods 21-40), and a high $\operatorname{cost}(\phi=400)$ in the third phase (periods 41-60). This ordering was reversed in the other six sessions, where sellers faced low costs of advertising in Phases I and III and a high cost in Phase II. We refer to these sessions as 'Lo-HiLo' sessions. Six sessions employed a Two-seller treatment, while the other six employed a Four-seller treatment. The design is summarized in Table 1 below. 


\begin{tabular}{|c|c|c|}
\hline \multicolumn{2}{|c|}{ Table 1. Summary of Experimental Design } \\
\hline & Two sellers & Four sellers \\
\hline Hi-Lo-Hi & 3 sessions & 3 sessions \\
\hline Lo-Hi-Lo & 3 sessions & 3 sessions \\
\hline
\end{tabular}

This design enables the effect of changes in advertising fees to be assessed by within-session comparisons. These comparisons can be made both for the case of $n=2$, and for the case of $n=$ 4. The effect of changes in the number of competitors can be also be assessed by making the relevant across-session comparisons. For the experimental parameters, the predictions for our various treatments are summarized in Table 2 .

\begin{tabular}{|c|c|c|c|c|}
\hline \multicolumn{5}{|c|}{ Table 2. Theoretical Predictions } \\
\hline & \multicolumn{2}{|c|}{$n=2$} & \multicolumn{2}{c|}{$n=4$} \\
\hline & $\phi=200$ & $\phi=400$ & $\phi=200$ & $\phi=400$ \\
\hline advertising propensity & 0.67 & 0.33 & 0.39 & 0.24 \\
\hline expected advertised price & 73 & 88 & 64 & 75 \\
\hline expected unadvertised price & 100 & 100 & 100 & 100 \\
\hline expected profits & 800 & 1000 & 367 & 433 \\
\hline expected price paid by loyals & 82 & 96 & 86 & 94 \\
\hline expected price paid by bargain-hunters & 73 & 93 & 63 & 82 \\
\hline
\end{tabular}

Notice that for the parameter values chosen, the comparative static predictions with respect to changes in rivalry $(n)$ are:

1. Advertising propensities decrease with rivalry. 
2. Greater rivalry lowers the price paid by price sensitive consumers.

3. Greater rivalry will increase prices paid by price insensitive consumers if advertising fees are sufficiently low. When fees are high, rivalry decreases the price these consumers pay for the good. We now turn to the results.

\section{Results}

\subsection{Overview}

Table 3 presents summary statistics for the various treatment combinations, averaging over all relevant phases and sessions. A comparison of the entries in this table with those in Table 2 reveal that with the exception of the two-seller low advertising fee treatment there are some quite substantial discrepancies in levels of behavior. Most noticeably, subjects advertise too frequently andoften price more aggressively than theory predicts.

In terms of the comparative static predictions, the advertising and pricing decisions made by subjects vary across treatments in the predicted direction. Advertising propensities decrease with both $\phi$ and $n$, and average advertised prices increase with $\phi$ and decrease with $n$, all as predicted. The implications of these decisions for expected profits and the expected prices paid by each type of consumer, however, get more mixed support. Prices paid by price sensitive consumers increase with advertising fees and decrease with $n$, exactly as predicted. Likewise, prices paid by price insensitive consumers increase with advertising fees, also as predicted. However, contrary to the theoretical predictions, increases in rivalry always reduces the prices paid by loyal customers - independent of advertising fees. Moreover, while profits to firms decline strongly with greater rivalry, the prediction that advertising fees act as a facilitating device is not borne out when $n=2$ and is only very modest for $n=4$. 


\begin{tabular}{|c|c|c|c|c|}
\hline \multicolumn{5}{|c|}{ Table 3. Results: Summary Statistics } \\
\hline & \multicolumn{2}{|c|}{$n=2$} & \multicolumn{2}{c|}{$n=4$} \\
\hline & $\phi=200$ & $\phi=400$ & $\phi=200$ & $\phi=400$ \\
\hline advertising propensity & 0.67 & 0.59 & 0.53 & 0.39 \\
\hline average advertised price & 75 & 82 & 63 & 69 \\
\hline average unadvertised price & 96 & 98 & 98 & 97 \\
\hline average profits & 803 & 792 & 290 & 302 \\
\hline average price paid by loyals & 82 & 89 & 80 & 86 \\
\hline average price paid by bargain-hunters & 74 & 83 & 52 & 66 \\
\hline
\end{tabular}

\subsection{Testing Comparative Static Predictions}

To assess the significance of these results we use non-parametric tests applied to session-level data. The advantage of this approach to analyzing the data is that it does not rely on any assumptions about the underlying data generation process within a session. We expect subjects to learn as they make decisions repeatedly, and we expect subjects to react to other subjects' decisions. Thus, while we have many observations per session, these observations should not be viewed as independent. On the other hand, we regard any summary statistic constructed from a single session to be independent from those constructed from other sessions. Thus, our approach yields exact tests without imposing strong assumptions about how subject choices are related to one another. Our null hypotheses state that changes in the market structure (i.e. in $n$ or $\phi$ ) have no impact on decisions or market outcomes, and we test these against one-sided alternative hypotheses suggested by the model.

Our first result concerns subjects' decisions about whether to advertise or not: 
Result 1. Sellers advertise less frequently when (i) the advertising cost is higher, and (ii) the number of sellers is higher.

Support for Result 1(i): Table 4 presents the proportion of decisions to advertise by phase for each session. In all twelve sessions, advertising propensities change from phase to phase in the direction predicted by the model—sellers advertise more frequently when the advertising fee is low. Under the null hypothesis the probability of observing advertising propensities move in the predicted direction between phases one and two twelve times out of twelve is 0.0002 . Thus the null hypothesis that advertising cost does not affect advertising propensities can be rejected in favor of the directional alternative implied by the model, at any conventional significance level.

\begin{tabular}{|c|c|c|c|c|c|c|c|}
\hline & \multicolumn{3}{|c|}{ Lo-Hi-Lo Sequence } & & \multicolumn{3}{|c|}{ Hi-Lo-Hi Sequence } \\
\hline & Phase 1 & Phase 2 & Phase 3 & & Phase 1 & Phase 2 & Phase 3 \\
\hline Two & 0.663 & 0.542 & 0.679 & Two & 0.671 & 0.792 & 0.725 \\
\hline Seller & 0.646 & 0.513 & 0.596 & Seller & 0.579 & 0.675 & 0.638 \\
\hline Sessions & 0.596 & 0.467 & 0.638 & Sessions & 0.533 & 0.754 & 0.617 \\
\hline Four & 0.542 & 0.438 & 0.583 & Four & 0.396 & 0.558 & 0.388 \\
\hline Seller & 0.538 & 0.433 & 0.550 & Seller & 0.392 & 0.554 & 0.354 \\
\hline Sessions & 0.504 & 0.375 & 0.513 & Sessions & 0.367 & 0.433 & 0.325 \\
\hline
\end{tabular}

Support for Result 1(ii): Table 4 also reveals that advertising propensities vary with the number of competing sellers in a systematic way. Consider phase one of the Lo-Hi-Lo sessions. The lowest advertising propensity of the three two-seller sessions is higher than the highest advertising propensity of the four-seller sessions. Under the null hypothesis such an extreme 
ordering would occur with probability $3 ! 3 ! / 6 !=0.05$. Thus we can reject the hypothesis that advertising propensities do not vary with the number of competitors in favor of the alternative that advertising propensities fall with $n$ for phase one of these sessions at a 5\% significance level. In fact, this is also true for all the other phases, and for all the phases of the Hi-Lo-Hi sequence, as well.

Next we consider advertised prices:

Result 2. Sellers advertise higher prices when (i) the advertising cost is higher, and (ii) the number of sellers is lower.

Support for Result 2. As advertising cost is manipulated between phase 1 and 2, the average advertised price moves in the predicted direction in all but two cases (indicated with asterisks in Table 5), so that we can reject the hypothesis that behavior is invariant to $\phi(p$-value $=0.019)$. A similar result applies to the transition from phase 2 to phase 3 ( $p$-value $=0.0002)$, since the average advertised price moves in the predicted direction in every single case. Also, note that in all phases of both advertising sequences advertised prices fall as the number of competitors is increased, in line with the theoretical prediction. Thus, for all phases of both advertising sequences, we reject at the 5\% significance level the hypothesis that advertised prices are invariant to $n$, in favor of the alternative predicted by the model. 


\begin{tabular}{|c|c|c|c|c|c|c|c|}
\hline \multicolumn{8}{|c|}{ Table 5. Average Advertised Prices } \\
\hline & \multicolumn{3}{|c|}{ Lo-Hi-Lo Sequence } & & \multicolumn{3}{|c|}{ Hi-Lo-Hi Sequence } \\
\hline & Phase 1 & Phase 2 & Phase 3 & & Phase 1 & Phase 2 & Phase 3 \\
\hline Two & 68.41 & 83.08 & 76.70 & Two & 81.58 & 76.71 & 82.61 \\
\hline Seller & 76.53 & 86.57 & 74.90 & Seller & 78.51 & 77.15 & 83.13 \\
\hline Sessions & 66.76 & 86.89 & 80.18 & Sessions & 76.94 & 76.66 & 80.02 \\
\hline Four & 56.02 & 72.26 & 65.34 & Four & 63.91 & 62.82 & 70.64 \\
\hline Seller & 59.35 & 68.42 & 65.14 & Seller & $65.78^{*}$ & $68.94 *$ & 73.18 \\
\hline Sessions & 57.71 & 70.50 & 65.92 & Sessions & $61.10^{*}$ & $61.84 *$ & 70.89 \\
\hline
\end{tabular}

Any seller that does not advertise should set a price of 100 in any treatment of our experiment. In fact a similar pattern is observed in all treatments - in the first few periods there are a few unadvertised prices below 100, but average unadvertised prices converge toward 100 as the session progresses. This is the only significant factor affecting average unadvertised prices:

Result 3. Average unadvertised prices do not vary systematically across treatments. In all treatments average unadvertised prices are somewhat lower than predicted (100) in phase one, but converge to within $1 \%$ of the predicted level by phase three.

Support for Result 3: We report average unadvertised prices in Table 6. There is a significant $n$ effect in phases one and three of the Lo-Hi-Lo sessions ( $p=0.10$ for each case on the basis of separate two-sided tests). Against this however, one should note that there is no evidence of a significant $n$ effect for phase two, or for any phase of the Hi-Lo-Hi sessions. Within session changes in unadvertised prices between phases one and two clearly indicate a learning effect-in 11 of 12 sessions unadvertised prices increase. However, this effect covers both transitions from 
low to high and from high to low advertising fees. A somewhat smaller effect is observed in the changes from phase two to three: in 9 of 12 sessions average unadvertised prices increase (and in one unadvertised prices remain at 100$)$.

\begin{tabular}{|c|c|c|c|c|c|c|c|}
\hline \multicolumn{8}{|c|}{ Table 6. Average Unadvertised Prices } \\
\hline & \multicolumn{3}{|c|}{ Lo-Hi-Lo Sequence } & & \multicolumn{3}{|c|}{ Hi-Lo-Hi Sequence } \\
\hline & Phase 1 & Phase 2 & Phase 3 & & Phase 1 & Phase 2 & Phase 3 \\
\hline Two & 91.07 & 98.44 & 99.38 & Two & 93.43 & 99.98 & 99.83 \\
\hline Seller & 89.45 & 98.62 & 99.67 & Seller & 93.76 & 98.78 & 99.67 \\
\hline Sessions & 92.95 & 99.21 & 99.56 & Sessions & 97.10 & 96.44 & 99.74 \\
\hline Four & 93.33 & 99.71 & 100.00 & Four & 91.71 & 99.93 & 100.00 \\
\hline Seller & 95.38 & 98.52 & 100.00 & Seller & 93.27 & 100.00 & 100.00 \\
\hline Sessions & 95.19 & 98.63 & 99.97 & Sessions & 91.02 & 99.74 & 99.44 \\
\hline
\end{tabular}

Taken together, these results indicate that while subjects decisions cannot be explained completely by the model, when the model predicts a change in subjects' decisions in response to changes in the market environment, the data exhibit a corresponding change.

Loyal consumers pay a high price if their seller does not advertise, and a somewhat lower price if their seller attempts to attract bargain-hunters. Since sellers are less likely to advertise when the advertising fee is high, and since advertised prices tend to be higher when the fee is high, we should expect from our earlier results that loyal consumers pay higher prices, on average in the $\phi=400$ treatment. Indeed, this is the case:

Result 4. Average prices paid by loyal consumers increase with advertising fees. 
Support for Result 4: As shown in Table 7, between phases one and two the average price paid by loyals moves in the predicted direction with respect to $\phi$ in all but the two cases (indicated by asterisks) where advertised prices move in the wrong direction. Thus we can reject the hypothesis that $\phi$ does not affect the expected price paid by loyals in favor of the directional alternative predicted by the model $(\mathrm{p}=0.019)$. Between phases two and three the average price paid by loyals moves in the predicted direction in all twelve sessions.

\begin{tabular}{|c|c|c|c|c|c|c|c|}
\hline \multicolumn{8}{|c|}{ Table 7. Average Prices Paid by Loyals } \\
\hline & \multicolumn{3}{|c|}{ Lo-Hi-Lo Sequence } & & \multicolumn{3}{|c|}{ Hi-Lo-Hi Sequence } \\
\hline & Phase 1 & Phase 2 & Phase 3 & & Phase 1 & Phase 2 & Phase 3 \\
\hline Two & 76.73 & 90.08 & 83.86 & Two & 85.14 & 81.51 & 87.39 \\
\hline Seller & 80.77 & 92.71 & 84.71 & Seller & 84.93 & 83.83 & 88.92 \\
\hline Sessions & 78.11 & 93.30 & 87.72 & Sessions & 86.75 & 81.50 & 87.63 \\
\hline Four & 74.40 & 87.69 & 79.84 & Four & 81.22 & 79.58 & 88.50 \\
\hline Seller & 77.09 & 86.16 & 80.65 & Seller & $82.12 *$ & $82.90 *$ & 89.71 \\
\hline Sessions & 76.53 & 88.35 & 82.50 & Sessions & $80.05^{*}$ & $83.07 *$ & 90.18 \\
\hline
\end{tabular}

What about the effect of increasing $n$ ? As shown in Table 2, the model predicts a small increase in the expected price paid by loyals when the advertising fee is low, and a small decrease when the advertising fee is high. Here our results are quite mixed. In phase 2 of Lo-HiLo and phase 1 of Hi-Lo-Hi an increase in the number of competitors leads to a significant decrease in the average price paid by loyals $(\mathrm{p}=0.05)$, but in the remaining four cases we fail to 
reject the null against the one-sided alternative suggested by the model. Perhaps this is not surprising given the modest changes predicted.

Table 8 shows the average price paid by bargain hunters in each phase of each session.

\begin{tabular}{|c|c|c|c|c|c|c|c|}
\hline \multicolumn{8}{|c|}{ Table 8. Average Price Paid by Bargain-Hunters } \\
\hline & \multicolumn{3}{|c|}{ Lo-Hi-Lo Sequence } & & \multicolumn{3}{|c|}{ Hi-Lo-Hi Sequence } \\
\hline & Phase 1 & Phase 2 & Phase 3 & & Phase 1 & Phase 2 & Phase 3 \\
\hline Two & 68.13 & 84.08 & 74.75 & Two & 79.95 & 73.06 & 80.11 \\
\hline Seller & 73.96 & 88.07 & 76.75 & Seller & 79.06 & 77.92 & 83.57 \\
\hline Sessions & 69.54 & 89.07 & 79.98 & Sessions & 79.79 & 72.82 & 80.24 \\
\hline Four & 47.49 & 67.74 & 52.39 & Four & 62.34 & 52.56 & 66.37 \\
\hline Seller & 49.84 & 62.11 & 51.37 & Seller & 61.09 & 57.64 & 71.64 \\
\hline Sessions & 47.91 & 67.75 & 55.86 & Sessions & 61.84 & 56.68 & 72.23 \\
\hline
\end{tabular}

Referring again to Table 2, the expected price paid by bargain-hunters is predicted to be higher when (i) the advertising fee is higher, and (ii) the number of sellers is lower. The predictions are confirmed by our data:

Result 5. Average prices paid by bargain-hunters increase when (i) the advertising fee is higher, and (ii) when the number of competitors is lower.

Support for Result 5: As shown in Table 8, as the advertising fee changes from phase to phase the average price paid by bargain-hunters moves in the predicted direction in every session ( $p$ value $=0.0002)$. Likewise, in all cases, average prices paid by bargain-hunters are lower for $n=$ 4 than for $n=2(\mathrm{p}$-value $=0.05)$. 
Our final result summarizes the extent to which profits fall with increases in rivalry, and are facilitated by increases in advertising costs.

\section{Result 6. Average profits (i) increase when there are fewer sellers, but (ii) are not} systematically affected by advertising costs.

Support for Result 6. As seen in Table 9, for any phase and any advertising fee sequence, profits are significantly lower when four sellers compete $(p$-value $=0.05)$.

\begin{tabular}{|c|c|c|c|c|c|c|c|}
\hline \multicolumn{8}{|c|}{ Table 9. Average Profit per Seller } \\
\hline & \multicolumn{3}{|c|}{ Lo-Hi-Lo Sequence } & & \multicolumn{3}{|c|}{ Hi-Lo-Hi Sequence } \\
\hline & Phase 1 & Phase 2 & Phase 3 & & Phase 1 & Phase 2 & Phase 3 \\
\hline Two & 736.68 & 828.31 & 815.84 & Two & $722.19 *$ & $769.05^{*}$ & $715.00 *$ \\
\hline Seller & 799.20 & 879.70 & 849.64 & Seller & $752.26^{*}$ & $835.53 *$ & $779.97 *$ \\
\hline Sessions & 766.73 & 907.56 & 878.69 & Sessions & 785.88 & $775.11 *$ & $760.57 *$ \\
\hline Four & 257.32 & 291.27 & 280.03 & Four & $279.01 *$ & $332.57 *$ & 357.23 \\
\hline Seller & $273.28 *$ & $271.48 *$ & $286.07^{*}$ & Seller & $272.97 *$ & $310.80 *$ & 342.37 \\
\hline Sessions & 272.47 & 318.32 & 312.58 & Sessions & $272.34^{*}$ & $284.74 *$ & 309.62 \\
\hline
\end{tabular}

However, there is no clear pattern to how advertising fees affect profits. Comparing phases one and two, profits move in the predicted direction in six of twelve sessions (four of six two-seller sessions and two of six four-seller sessions). Comparing phases two and three, profits move in the predicted direction in eight of twelve sessions (three of six two-seller sessions and five of six four-seller sessions). As a result, the prediction that profits increase with advertising fees gets mixed support from our experimental data. 
Given that behavior changes with the market environment in accordance with theoretical predictions, it may seem surprising that the comparative static prediction about profits and advertising fees gets such little support. Essentially, the reason is that in order for sellers to benefit from higher advertising fees, it is not enough that they reduce their propensity to advertise and charge higher advertised prices. The magnitude of the shifts must also be sufficient to offset the direct effect of the increase in fee on profits. Thus, although subjects reduce their advertising propensities when advertising fees increase, in several sessions they do not reduce their propensities enough.

Figure 1. Theoretical and Empirical Distributions of Surplus $n=2$

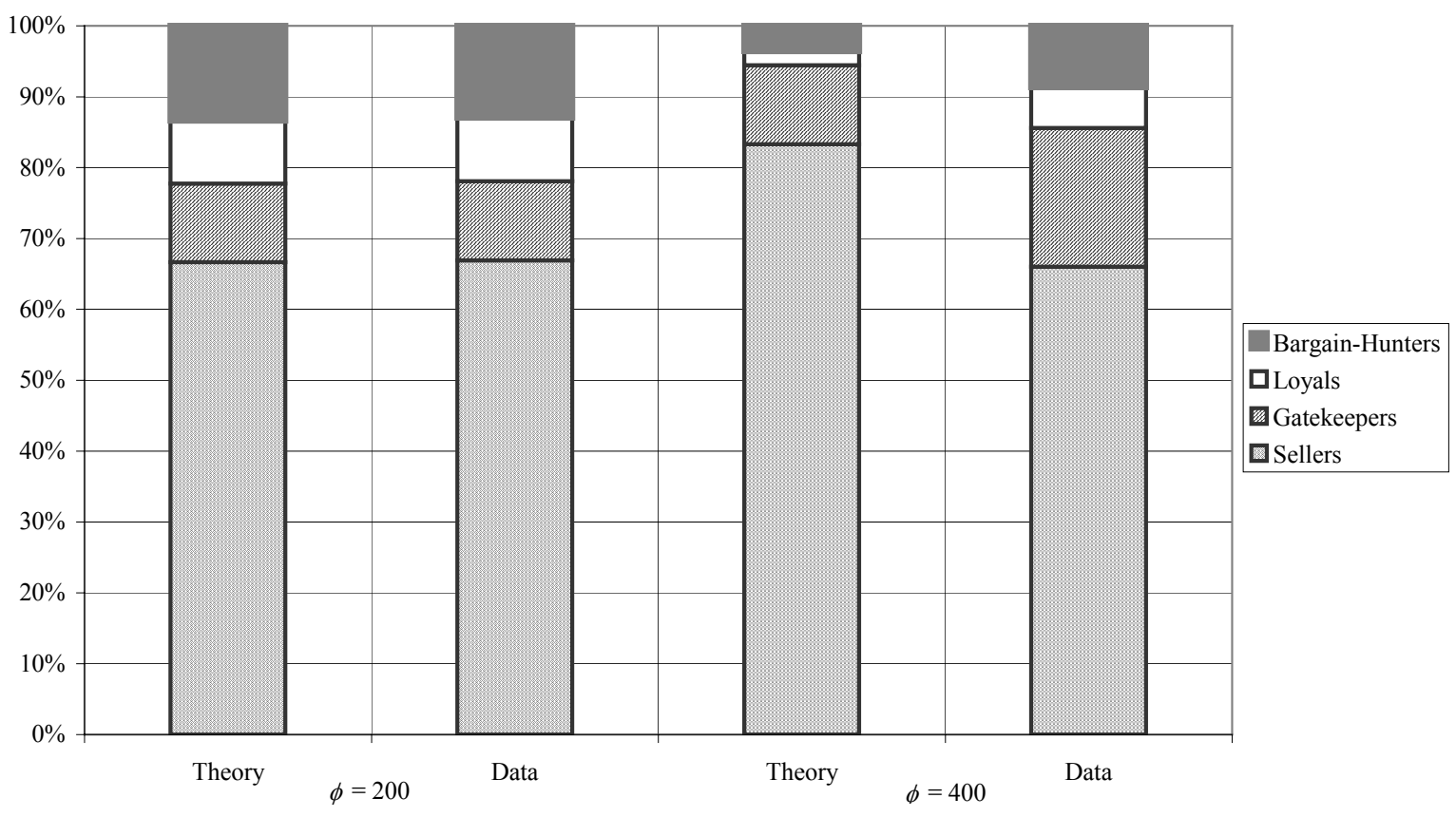

In fact, as shown in Figure 1, aggregating over all Two-seller sessions, profits vary little with advertising fees. Part of the reason for this is that when advertising fees double from 200 to 400, sellers increase their advertising expenditures (i.e. "gatekeepers surplus"), whereas theory predicts advertising propensities should fall so as to keep advertising expenditures constant. Also, in theory sellers should increase prices, to the extent that consumer surplus is almost 
eliminated, while in fact they increase prices less than this on average. Figure 2 shows that a similar accounting exercise applies to the Four-seller sessions with similar results.

Figure 2. Theoretical and Empirical Distributions of Surplus

$$
n=4
$$

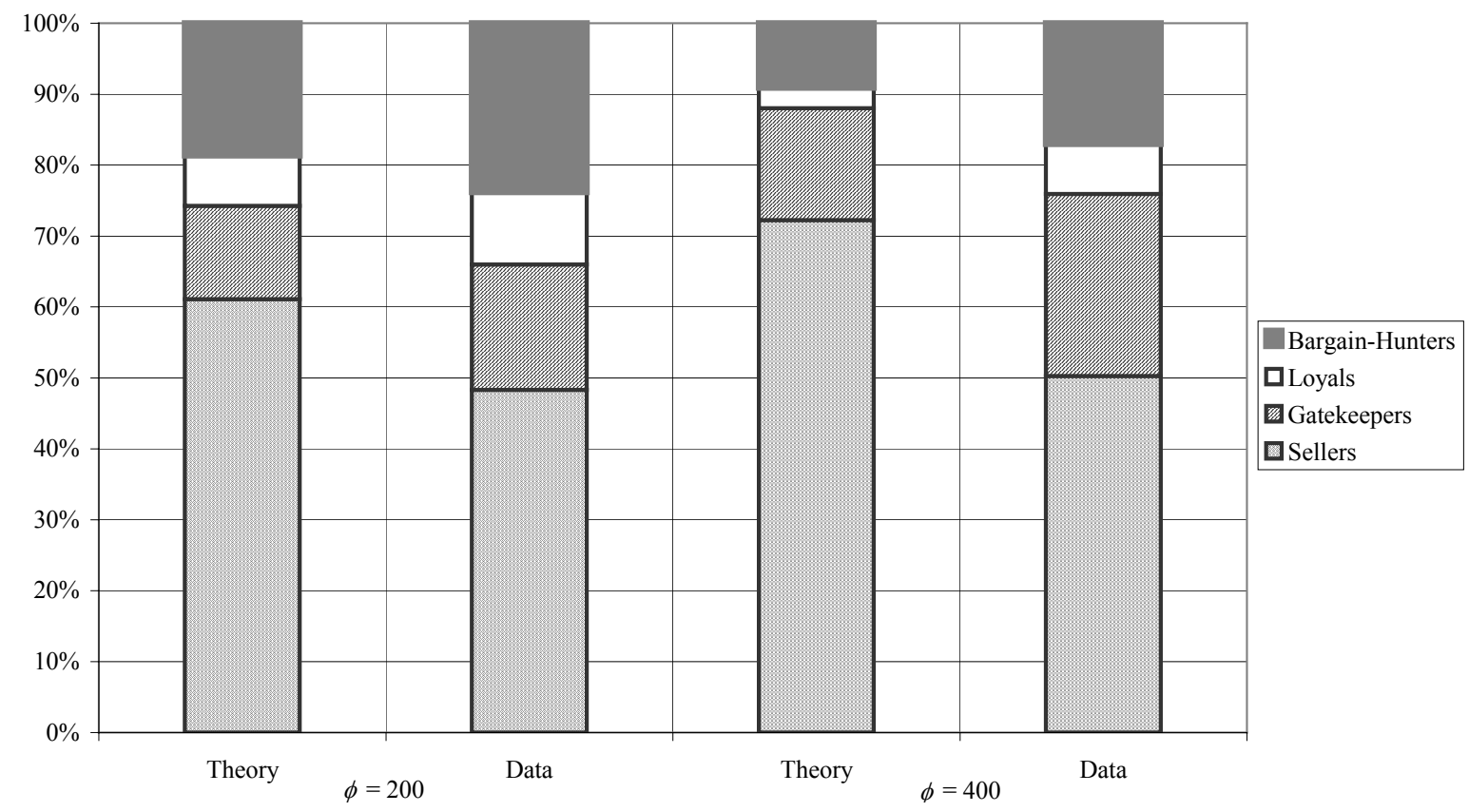

\section{Discussion and Conclusion}

Our experiment provides "mixed" support for the performance of mixed strategy predictions in a complex setting. On the one hand, as in previous experiments with (simpler) games involving mixed strategy equilibria, we observe some systematic departures from equilibrium play. Interestingly, these departures point in the direction of more aggressive and more competitive behavior than the theory predicts. Subjects advertise too frequently and set too low an advertised price. Further, increases in rivalry tend to magnify these competitive effects leading to profits that are lower than theoretical predictions. Moreover increases in advertising fees have a much weaker effect on this competitive behavior than predicted, with the result that sellers fail to exploit this facilitating device. 
On the other hand, the theory is very successful at predicting how subjects' decisions change as the underlying market environment changes. As advertising fees and numbers of competitors are manipulated, subjects' decisions change systematically in the direction predicted by comparative static analysis based on the mixed strategy equilibrium. Likewise, the interaction effects of changes in pricing and advertising generates the predicted impact on consumers - they are hurt by higher advertising fees.

To us, these results seem reminiscent of those observed in first-price auctions, where subjects consistently overbid relative to the risk-neutral Nash equilibrium predictions. A leading explanation in that model is that subjects are prone to both decision errors and risk-aversion and that, together, this leads to systematic deviations in the direction of increased competitiveness (see Goeree, Holt and Palfrey, 2002). However, in our set up, unlike in first-price auctions, excessively competitive behavior cannot be explained by risk aversion. In fact, it can be shown that risk aversion reduces equilibrium advertising probabilities, and that in the simple version of the model with zero advertising fees, risk aversion leads to higher, not lower, prices. ${ }^{6}$

The overly aggressive marketing behavior displayed by subjects appears analogous to many real-world situations. Specifically, an important motivation for studying this model is its resemblance to the decisions faced by firms in e-retailing. The supremacy of marketing over profits (the quest for "eyeballs"), with predictably disastrous results, has been well-documented in the business press. In some sense, we are witnessing a similar phenomenon in our experiments. An important direction for future research is to postulate the theoretical and psychological underpinnings of this "irrational exuberance" and then develop tests to discriminate among these.

\footnotetext{
${ }^{6} \mathrm{~A}$ formal demonstration of these claims is provided in Appendix B.
} 


\section{References}

Amaldoss, W. and S. Jain (2002). David vs. Goliath: An Analysis of Asymmetric MixedStrategy Games and Experimental Evidence. Management Science, 48, 972-991.

Baye, M. and Morgan, J. (2001). Information Gatekeepers on the Internet and the Competitiveness of Homogeneous Product Markets. American Economic Review, 91, 454-474.

Binmore, K., J. Swierzbinski and C. Proulx (2001). Does Minimax Work? An Experimental Study. Economic Journal, 111, 445-464.

Brown-Kruse, J., S. Reynolds and V. Smith (1994). Bertrand-Edgeworth Competition in Experimental Markets. Econometrica, 62, 343-371.

Camerer, C. (2003). Behavioral Game Theory: Experiments in Strategic Interaction. Princeton University Press, Princeton, NJ.

Collins, R. and K. Sherstyuk (2000). Spatial Competition with Three Firms: An Experimental Study. Economic Inquiry, 38, 73-94.

Goeree, J., C. Holt and T. Palfrey. (2002). Quantal Response Equilibrium and Overbidding in Private-Value Auctions. Journal of Economic Theory, 104, 247-272.

Morgan, J., H. Orzen and M. Sefton (2003). An Experimental Study of Price Dispersion. mimeo, http: //www.nottingham.ac.uk/economics/cedex/papers/mos3.pdf.

Rapoport, A. and W. Amaldoss (2000). Mixed Strategies and Iterative Elimination of Strongly Dominated Strategies: An Experimental Investigation of States of Knowledge. Journal of Economic Behavior and Organization, 42, 483-521.

Varian, H. (1980). A Model of Sales. American Economic Review, 70, 651-659. 


\section{Appendix A - Instructions}

\section{General rules}

This session is part of an experiment in the economics of decision making. If you follow the instructions carefully and make good decisions, you can earn a considerable amount of money. At the end of the session you will be paid, in private and in cash, an amount that will depend on your decisions.

There are twelve people in this room who are participating in this session. It is important that you do not talk to any of the other people in the room until the session is over.

The session will consist of 60 periods. You begin with an initial balance of 9,000 points, and in each period you can earn additional points (in some periods these may be negative). At the end of the experiment you will be paid based on your total point earnings, i.e. your initial balance plus points earned from all 60 periods. Points will be converted to cash using an exchange rate of 30 points $=1 \mathrm{p}$. Notice that the more points you earn, the more cash you will receive at the end of the session.

\section{Description of a period}

Each person in the room has been designated as a seller. In each period $\{$ six $\}$ [three] markets will operate, and you will be randomly allocated to one of these. Similarly, the other sellers will be randomly allocated to markets. You will be competing with the [three] other \{seller\} [sellers] who \{is\} [are] randomly allocated to your market. Your point earnings will depend on the decisions in your market. Because sellers are randomly allocated to markets at the beginning of each period, the identity of your [three] competitor[s] will change from period to period.

At the beginning of each period you must decide what price to charge. You make your decision by entering a price (any whole number between 0 and 100) on your terminal. Then, after entering this price, you decide whether or not to pay a fee to advertise it.

After all sellers have made their decisions the computer will calculate your point earnings for the period. Your point earnings will be equal to the price you charge times the number of units you sell, minus the advertising cost:

$$
\text { point earnings }=(\text { price } \times \text { number of units sold })-\text { advertising cost }
$$

If you decided not to advertise your price, you will incur zero advertising cost. If you decided to advertise your price you will incur an advertising cost, as explained later.

The number of units sold are calculated as follows:

(A) You automatically sell [3] $\{6\}$ units whether you advertise or not.

(B) If no one in your market advertises, you sell an additional [3] \{6\} units.

(C) If you advertise and charge the lowest advertised price in your market, you sell an additional 12 units. (If you tie for the lowest advertised price in your market, the 12 extra units will be evenly divided between you and [the competitor(s) you are tied with] \{your competitor\}.)

At the end of each period the decisions of each seller will be displayed on your terminal. (You will be informed of the decisions of all sellers in all markets; the rows corresponding to your market will be highlighted.) The terminal will also display the number of units sold, and the point earnings, of each seller. Your terminal will also display your point earnings for that period, your point earnings from the previous five periods, and your accumulated point earnings.

\section{Differences between periods}

All periods are identical except that your competitors will be changing from period to period, and the advertising cost will be changing from phase to phase.

In Phase One (periods 1 to 20), the advertising cost is 400.

In Phase Two (periods 21 to 40), the advertising cost is 200.

In Phase Three, (periods 41 to 60), the advertising cost is 400 . 


\section{Appendix B. The Effect of Risk Aversion.}

\section{(1) Risk Aversion and Advertising}

In the following we show that risk aversion would lower the equilibrium advertising probability.

First, note that in equilibrium charging the reservation price must give the same expected utility whether or not a player advertises this price; thus,

$$
q u\left(r \frac{N}{n}\right)+(1-q) u\left(r \frac{N-\mu}{n}\right)=q u\left(r \mu+r \frac{N-\mu}{n}-\phi\right)+(1-q) u\left(r \frac{N-\mu}{n}-\phi\right)
$$

where $q=(1-\alpha)^{n-1}$. This can be rearranged to give

$$
\frac{q}{1-q}=\frac{u\left(r \frac{N-\mu}{n}\right)-u\left(r \frac{N-\mu}{n}-\phi\right)}{u\left(r \mu+r \frac{N-\mu}{n}-\phi\right)-u\left(r \frac{N}{n}\right)}
$$

Now note that under risk aversion we have

$$
\frac{u\left(r \frac{N-\mu}{n}\right)-u\left(r \frac{N-\mu}{n}-\phi\right)}{\left(r \frac{N-\mu}{n}\right)-\left(r \frac{N-\mu}{n}-\phi\right)}>\frac{u\left(r \mu+r \frac{N-\mu}{n}-\phi\right)-u\left(r \frac{N}{n}\right)}{\left(r \mu+r \frac{N-\mu}{n}-\phi\right)-\left(r \frac{N}{n}\right)}
$$

which implies that

$$
\frac{q}{1-q}>\frac{n \phi}{(n-1) \mu r-n \phi}
$$

or

$$
q>\frac{n \phi}{(n-1) \mu r}
$$

which is equivalent to

$$
\alpha<1-\left(\frac{n \phi}{(n-1) \mu r}\right)^{\frac{1}{n-1}}
$$




\section{(2) Risk Aversion and Pricing}

Next, we show that when there is no advertising fee the equilibrium distribution of prices is stochastically increasing in the degree of risk aversion. When there is no advertising fee, $F(p)$, the equilibrium distribution of prices, is strictly increasing on the support

$$
[r(N-\mu) /(N+\mu(n-1)), r]
$$

regardless of risk preferences. Fix a price, $p$, such that $r(N-\mu) /(N+\mu(n-1))<p<r$.

A seller that charges price $r$ receives a profit of $r(N-\mu) / n$. Scale utility function $\mathrm{u}(\cdot)$ so that the utility of this profit equals 1 , i.e.

$$
u(r(N-\mu) / n)=1
$$

For the price $p$, a seller charging this price will receive a profit of either $p(N-\mu) / n$ or $p(\mu+(N-$ $\mu) / n)$. Let the utility of the former profit equal 0 , i.e.

$$
u(p(N-\mu) / n)=0
$$

and let $u$ denote $u(p(\mu+(N-\mu) / n))$.

Since in equilibrium the seller is indifferent between charging $r$ and $p$, we must have

$$
1=\left(1-F_{u}(p)\right)^{n-1} u
$$

Scale a more risk averse utility function $v()$ in the same way, so that $v=v(p(\mu+(\mathrm{N}-\mu) / n))<u$. Under this utility function the distribution of prices must satisfy

$$
1=\left(1-F_{v}(p)\right)^{n-1} v
$$

Thus,

$$
\left(1-F_{u}(p)\right)^{n-1} u=\left(1-F_{v}(p)\right)^{n-1} v
$$

Since $v<u$ we have $F_{\mathrm{u}}(p)>F_{v}(p)$ for all $p \in .(r(N-\mu) /(N+\mu(n-1)), r)$ 